\title{
openheart Absorb BRS for in-stent restenosis: the final bow before (scaffold) collapse?
}

\author{
Diego Arroyo, Stéphane Cook
}

To cite: Arroyo D, Cook S. Absorb BRS for in-stent restenosis: the final bow before (scaffold) collapse?. Open Heart 2021;8:e001838. doi:10.1136/ openhrt-2021-001838

Accepted 23 September 2021

\section{Linked}

http://dx.doi.org/10.1136/ openhrt-2021-001776

Check for updates

(c) Author(s) (or their employer(s)) 2021. Re-use permitted under CC BY-NC. No commercial re-use. See rights and permissions. Published by BMJ.

Cardiology, University and Hospital Fribourg, Fribourg, Switzerland

Correspondence to Dr Diego Arroyo; diego.arroyo@ h-fr.ch
Restenosis in drug-eluting stents (DES) complicates $3 \%-8 \%$ of procedures at 1 year, $8 \%-15 \%$ at 2 years and $8 \%-31 \%$ at 10 years. ${ }^{12}$ Restenosis after plain-old balloon angioplasty (POBA) is due to negative remodelling, while restenosis after bare metal stent (BMS) is mostly related to neointimal hyperplasia. However, restenosis after DES is due to the combination of neointimal hyperplasia and early neoatherosclerosis. ${ }^{3}$ Putative causes for restenosis after DES include mechanical factors, such as miss, gap, polymer peeling, media barotrauma, stent underexpansion, platform fracture or inhomogeneous strut distribution, and biological factors, such as hypersensitivity reactions or drug resistance. DES restenosis is dynamic, spanning from focal $(<2$ years) to a diffuse pattern ( $>5$ years). This differs from restenosis after BMS, and unfortunately, is more difficult to treat.

Treatment options include POBA with conventional balloon, scoring balloon, cutting balloon, paclitaxel (or sirolimus)eluting balloon and placement of a new DES or coronary artery bypass graft surgery. Laser and intracoronary endobrachytherapy have gradually been abandoned. Current European guidelines favour the implantation of a new DES or the use of drug-eluting balloons.

In this issue of the journal, Madanchi et al present an alternative treatment: the implantation of a bioresorbable vascular scaffold (BRS). ${ }^{4}$ BRS was designed to provide a temporary mechanical support, thought to increase lumen size and flow, while disappearing over time (around 3 years) in the hope of restoring vasomotor tone and normal coronary physiology. In theory, late lesion and metallic stent-related events should be mitigated. Eight years ago, the implantation of BRS in DES restenosis made sense since the platform guaranteed a good immediate angiographic result with no additional metallic layer on the long run. Several trials were initiated but, since the retrieval of BRS from the market, none have been published so far.

Indeed, despite reassuring initial reports and short-term outcomes, concerning issues rapidly emerged. In a combined analysis from the ABSORB trials with 3-year follow-up, significant increases in the risk of target vessel myocardial infarction and target lesion revascularisation (TLR), as well as early and late scaffold thrombosis (ST), were observed compared with contemporary DES. ${ }^{5}$ Dedicated implantation protocols improved the risk of TLR, ${ }^{67}$ but ST remained a concern, and no benefit, such as restored vasoreactivity, could be demonstrated. ${ }^{8}$ Although BRS did not survive these disappointing results, long-term outcomes are paramount and still need to be analysed as potential positive effects would be expected once the platform is completely resorbed.

In the 5-year follow-up of the ABSORB III trial, target lesion failure was $17.5 \%$ vs $15.2 \%$ for DES $(p=0.15)$. However, target vessel myocardial infarction $(10.4 \%$ vs $7.5 \% ; \mathrm{p}=0.04)$ and $\mathrm{ST}$ rates $(2.5 \%$ vs $1.1 \%$; $\mathrm{p}=0.03)$ were higher. As suspected, a time dependency, from 3 years onwards, was observed where the Absorb BRS displayed similar outcomes to DES, and the ischaemic complications seemed to subside. An important caveat is that $42.8 \%$ of patients continued dual antiplatelet therapy until 5 years. ${ }^{9}$

Other trials with long-term follow-ups have reported acceptable outcomes such as the ABSORB JAPAN trial, in which TLR was $10.2 \%$, TVR $15.0 \%$, and no different to DES with no ST observed from 3 years onwards. ${ }^{10}$ In the Everbio-2 trial, 5-year outcomes were similar between BRS and other DES with target vessel myocardial infarction rates of $4 \%$ and TLR rates of $19 \% .^{11}$ 
Thus, the appealing concept of a dissolving device has invariably translated into disappointing clinical results up to 3 years, and unfortunately, no clear advantage beyond that. ${ }^{12}$

\section{WHAT ABOUT BRS IN TREATING RESTENOSIS AFTER DES?}

The evidence relies on the Lucerne experience, ${ }^{4}$ and the authors should be congratulated for filling the gap and providing a rigorous, single-centre observation in 89 patients over a median of 5-year follow-up. Lesions were complex, as $73 \%$ had diffuse, proliferative and even occlusive restenosis making comparisons with contemporary trials very hazardous. Although the initial outcomes were encouraging, they observed a steep rise in target vessel revascularisation (TVR) and TLR from 1 year onwards, peaking at a staggering $48 \%$ and $44 \%$ at 5 years, respectively. The rates of ST were high and continued to increase over the follow-up period, peaking at a cumulative rate of $8.4 \%$. These rates are significantly higher than other contemporary trials assessing in-stent restenosis treatment with either drug-coated balloons or DES.

Patients with restenosis are at higher risk of recurrent events, either from an inherently aggressive form of coronary artery disease, suboptimal cardiovascular risk factor management, or anatomical and procedural issues. That a high-risk patient population such as the one studied did poorly on the long term is no surprise. How much worse did they do because of BRS implantation is uncertain?

The study highlights the singularity of in-stent restenosis and hints once again towards different pathophysiological processes compared with de novo atherosclerotic coronary artery disease.

Contributors DAA and SC equally contributed to draft and write the manuscript.

Funding The authors have not declared a specific grant for this research from any funding agency in the public, commercial or not-for-profit sectors.

Competing interests None declared.

Patient consent for publication Not applicable.

Provenance and peer review Commissioned; internally peer reviewed.
Open access This is an open access article distributed in accordance with the Creative Commons Attribution Non Commercial (CC BY-NC 4.0) license, which permits others to distribute, remix, adapt, build upon this work non-commercially, and license their derivative works on different terms, provided the original work is properly cited, appropriate credit is given, any changes made indicated, and the use is non-commercial. See: http://creativecommons.org/licenses/by-nc/4.0/.

ORCID iD

Stéphane Cook http://orcid.org/0000-0003-1221-2978

\section{REFERENCES}

1 Palhais N, Arroyo D, Lehmann S, et al. Ten-year clinical followup after sirolimus-eluting stent implantation. Am Heart $J$ 2014;167:893-9.

2 Miura K, Kadota K, Habara S, et al. Ten-year clinical outcomes after sirolimus-eluting stent implantation: impact of an in-stent restenosis target lesion. Am Heart J 2016;175:47-55.

3 Otsuka F, Byrne RA, Yahagi K, et al. Neoatherosclerosis: overview of histopathologic findings and implications for intravascular imaging assessment. Eur Heart J 2015;36:2147-59.

4 Madanchi M, Cioffi GM, Attinger-Toller A, et al. Long-term outcomes after treatment of in-stent restenosis using the absorb everolimuseluting bioresorbable scaffold. Open Heart 2021;8:e001776.

5 Ali ZA, Gao R, Kimura T, et al. Three-Year outcomes with the absorb Bioresorbable scaffold: Individual-Patient-Data meta-analysis from the absorb randomized trials. Circulation 2018;137:464-79.

6 Stone GW, Ellis SG, Gori T, et al. Blinded outcomes and angina assessment of coronary bioresorbable scaffolds: 30-day and 1 -year results from the absorb IV randomised trial. Lancet 2018;392:1530-40.

7 Smits PC, Chang CC, Chevalier B, et al. Bioresorbable vascular scaffold versus metallic drug-eluting stent in patients at high risk of restenosis: the COMPARE-ABSORB randomised clinical trial. Eurolntervention 2020;16:645-53.

8 Serruys PW, Chevalier B, Sotomi Y, et al. Comparison of an everolimus-eluting bioresorbable scaffold with an everolimus-eluting metallic stent for the treatment of coronary artery stenosis (absorb II): a 3 year, randomised, controlled, single-blind, multicentre clinical trial. Lancet 2016;388:2479-91.

9 Kereiakes DJ, Ellis SG, Metzger DC, et al. Clinical outcomes before and after complete everolimus-eluting Bioresorbable scaffold resorption: five-year follow-up from the absorb III trial. Circulation 2019;140:1895-903.

10 Kozuma K, Tanabe K, Hamazaki Y, et al. Long-term Outcomes of Absorb Bioresorbable Vascular Scaffold vs. Everolimus-Eluting Metallic Stent- a randomized comparison through 5 years in Japan. Circ J 2020;84:733-41.

11 Schukraft S, Arroyo D, Togni M, et al. Five-year angiographic, OCT and clinical outcomes of a randomized comparison of everolimus and biolimus-eluting coronary stents with everolimus-eluting bioresorbable vascular scaffolds. Catheter Cardiovasc Interv 2021. doi:10.1002/ccd.29837. [Epub ahead of print: 26 Jun 2021].

12 Goel S, Pasam RT, Chava S, et al. Three to four years outcomes of the absorb bioresorbable vascular scaffold versus secondgeneration drug-eluting stent: a meta-analysis. Catheter Cardiovasc Interv 2020;95:216-23. 